УДК 63

DOI $10.21661 / \mathrm{r}-116857$

Д.А. Ободов, С.Ф. Демидов, В.А. Савельев, А.П. Ивкина

ЭКСПЕРИМЕНТАЛЬНОЕ ИЗУЧЕНИЕ

ПЛОТНОСТИ РАСПРЕДЕЛЕНИЯ ЧАСТИЦ МАТЕРИАЛА

В ШНЕКОВОЙ УСТАНОВКЕ

Аннотация: в работе проведены экспериментальные исследования плотности распределения частии смеси пшениць, овса, ржи для корма поросят при инфракрасном нагреве по времени пребывания и температуры на выходе из установки. Цель исследования - изучить качество обработки продукта при помощи установок со шнеком и со шнеком с установленной круглой перемычкой на пере шнека. Шнековые установки с инфракрасными излучателями выделенной длины волны дают возможность интенсивного и непрерывного процесса термообработки. Авторы использовали оптимальные параметры проведения процесса со шнеком и со шнеком с установленной круглой перемычкой на пере шнека. Параметры шнековой установки при проведении исследования составляли: число оборотов шнека 10 об/мин, плотность теплового потока $12 \mathrm{\kappa Bm} / \mathrm{M}^{2}$, производительность 250 кг/ч.

Ключевые слова: плотность распределения, исследование, инфракрасное излучение, частищы, шнековая установка, корм, температура.

D.A. Obodov, S.F. Demidov, V.A. Savelyev, A.P. Ivkina

\title{
EXPERIMENTAL STUDY OF THE DENSITY DISTRIBUTION OF THE PARTICLES OF THE MATERIAL IN SCREW INSTALLATION
}

Abstract: the experimental studies of density distribution of the particles of a mixture of wheat, oats, rye to feed pigs by infrared heating at the time of stay and temperature at the exit of the installation. The purpose of the work is to study the quality of treatment of the product with the settings with the screw and the screw with installed round jumper on the pen of the screw. Screw installations with infrared emitters of selected wavelength give the opportunity for intense and continuous heat treatment 
process. The authors used the optimal parameters of the process with the screw and the screw with installed round jumper on the pen of the screw. The parameters of screw installation during the study were the following: the number of revolutions of the screw was $10 \mathrm{rpm}$, density of heat flux was $12 \mathrm{~kW} / \mathrm{m}^{2}$, output capacity - $250 \mathrm{~kg} / \mathrm{h}$.

Keywords: density distribution, research, infrared radiation, particles, screw installation, food, temperature.

Шнековые установки с инфракрасными излучателями выделенной длины волны дают возможность организации интенсивного и непрерывного процесса термообработки корма для молодняка поросят [1;2]. Непрерывность подачи частиц кормовой смеси для поросят в шнековую установку приводит к неравномерности по времени пребывания отдельных частиц, в зоне воздействия температурного поля. Длительность процесса обычно рассматривается по среднему времени пребывания частиц материала в установке [3; 4]:

$$
\tau_{\mathrm{cp}}=\frac{G_{\mathrm{an}}}{G},
$$

где $G_{\text {ап }}$ - количество материала находящегося в установке, кг;

$G$ - расход материала, $\frac{\kappa \Gamma}{\mathrm{c}}$;

Среднему времени пребыванию соответствует и средняя температура корма для поросят, на выходе из установки. Следовательно, некоторая часть выгружаемых из установки частиц обладает температурой $t>t_{\mathrm{cp}}$ и $t<t_{\mathrm{cp}}$ [5].

Данное исследование посвящено оценке качества обработанного материала по времени пребывания при термообработке корма поросят инфракрасным излучением выделенной длины волны в шнековой установке и кондуктивным нагревом от стенки установки [6,7]. Установка состоит из двух шнеков с диаметром 150 мм, длина каждого составляет 3 м, одного бункера с шиберным узлом загрузки, двух редукторов, двух частотных преобразователей FR-S540-0,4; 3,7-EC и 6 греющих блоков. Для измерения температуры нагрева корма и стенки установки использовали инфракрасный пирометр RaytekMiniTempMT6 [8; 9]. 
Опыты проводились следующим образом. После выхода установки на режим, вводилось определённое количество 5 кг меченого материала (М). В момент ввода меченого материала включался секундомер. На выходе из установки с инфракрасными излучателями отбирались пробы, в которых определялось количество меченых частиц. Так как отбор каждой пробы производился за определенный интервал времени, то по весу пробы, отнесенному ко времени отбора, можно судить о производительности установки, качестве обработки исследуемого материала [10; 11].

В процессе опытов использовали оптимальные параметры проведения процесса со шнеком и со шнеком с установленной круглой перемычкой на пере шнека. Каждый опыт заканчивался изменением количества меченых частиц, выходящих из установки за время $\Delta \tau[12]$.

Обработка полученных данных сводилась к построению графика (рис. 1).

$$
\frac{P}{M \cdot \Delta \tau}=f(\tau)
$$

где $P$ - масса меченых частиц в расчете на абсолютно сухое вещество в пробе, отбираемой в течение промежутка времени $\Delta \tau$;

$\mathrm{M}$ - полная масса меченых частиц, вошедших в установку в момент времени $\tau=$ 0 в расчете на абсолютно сухое вещество;

$\tau$ - текущее время после ввода меченого материала.

На рисунке 1 приведены графики экспериментального распределения меченых частиц при работе установки (рис. 1) для шнека (кривая 1) и для шнека с установленной круглой перемычкой на пере шнека (кривая 2) при числе оборотов шнека 10 об/мин и плотности теплового потока 12 кВт/м². 


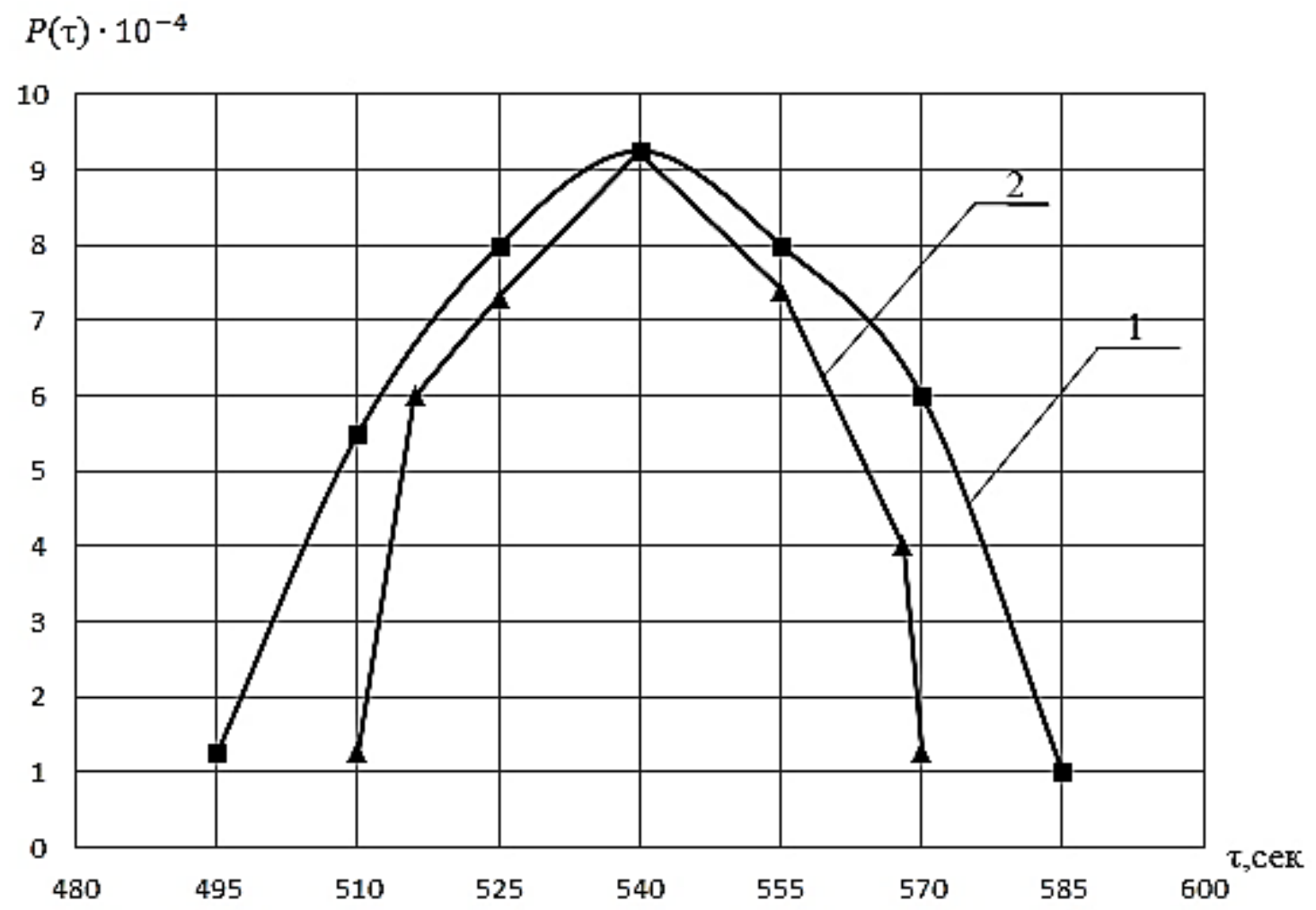

Рис. 1. Зависимость распределения меченых частиц от времени пребывания при работе установки для шнека (кривая 1) и для шнека с установленной круглой перемычкой на пере шнека (кривая 2)

Из графиков видно, что плотность распределения частиц корма для поросят на выходе в шнеке с установленной круглой перемычкой на пере шнека равномернее. Так, первые частицы в установке с перемычкой на шнеке выходят при среднем времени обработки 540 с с 510 с, а на установке со шнеком с 495 с.

Время обработки при прочих условиях больше, время нахождения частиц увеличивается на 15-17 с. 


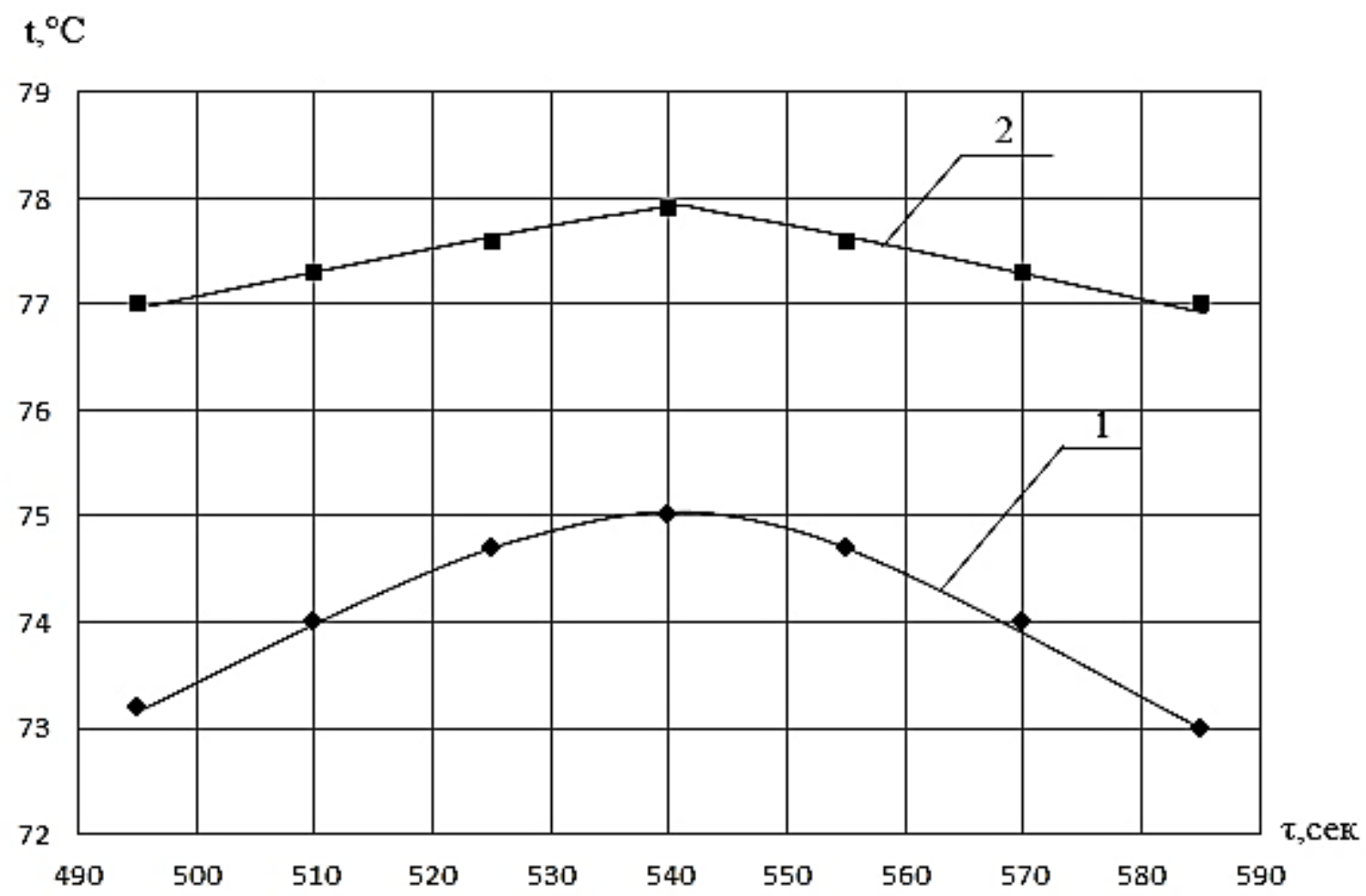

Рис. 2. Графики экспериментального распределения температур меченых частиц корма для поросят на выходе установки для шнека (кривая 1)

и для шнека с установленной круглой перемычкой на пере шнека (кривая 2)

Из графиков видно, что среднее время пребывания продукта в установке при 540 с, достигает температуры частиц на выходе установки для шнека (кривая 1) от 73 до $75^{\circ} \mathrm{C}$, а для шнека с установленной круглой перемычкой на пере шнека (кривая 2) от 77 до $78^{\circ} \mathrm{C}$. Объясняется это улучшением качества перемешивания при использовании круглой перемычкой на пере шнека и увеличении времени пребывания в зоне инфракрасного излучения и как следствие повышением температуры частиц на выходе на $3-4^{\circ} \mathrm{C}$.

Вывод: проведенное экспериментальное исследование показало, что работа шнековой установки с перемычкой на пере шнека, по сравнению со шнеком без перемычки эффективнее. Таким образом, температура частиц кормовой смеси на выходе из установки увеличилась на $3-4^{\circ} \mathrm{C}$, что позволяет нам увеличить температуру частиц на выходе из установки, степень денатурации белка и усвояемость протеина. 


\section{Список литературы}

1. Демидов А.С. Сушка семян подсолнечника инфракрасным излучением / А.С. Демидов, Б.А. Вороненко, С.Ф. Демидов // Новые технологии. - 2011. Вып. №3. - С. 25-30.

2. Пелевин А.Д. Комбикорма и их компоненты. - М.: ДеЛипринт, 2008. 519 c.

3. Тюрев Е.П. Эффективность теплотехнических процессов обработки пищевых продуктов ИК-излучением: Дис. ... д-ра техн. наук. - М., 1990. - 475 с.

4. Антипов С.Т. Машины и аппараты пищевых производств: Учебник для вузов. Кн. 1 / С.Т. Антипов, И.Т. Кретов, А.Н. Остриков, О.А. Ураков; под ред. В.А. Панфилова. - М.: КолосС, 2009. - 608 с.

5. Касаткин А.Г. Основные процессы и аппараты химической технологии: Учебник. - М.: Химия, 1973. - 752 с.

6. Демидов С.Ф. Исследование температурного поля инфракрасной нагревательной системы для сушки зародышей зерна пшеницы и ржаных отрубей / С.Ф. Демидов, Б.А. Вороненко, С.С. Беляева, В.И. Марченко // Научный журнал НИУ ИТМО. Серия: Процессы и аппараты пищевых производств. - 2013. - №2 .

7. Демидов С.Ф. Сушка морских водорослей инфракрасным излучением / С.Ф. Демидов, Б.А. Вороненко, Д.А. Ободов // Научный журнал НИУ ИТМО. Серия «Процессы и аппараты пищевых производств». - 2014. - №2.

8. Ободов Д.А. Источники инфракрасного излучения с энергоприводом для термообработки пищевых продуктов / Д.А. Ободов, С.Ф. Демидов, Б.А. Вороненко // Процессы и аппараты пищевых производств. - 2011. - №1.

9. Абрамов О.В. Расчет и конструирование машин и аппаратов пищевых производств: Учебник для вузов / О.В. Абрамов, А.Н. Остриков. - СПб.: ГИОРД, 2003. $-352 \mathrm{c}$.

10. Кундышев П. Повышение переваримости кормов свиньями // Комбикорма. - №1. - 2009. - С. 17. 
11. Медведев П.В. Комплексная оценка потребительских свойств зерна и продуктов его переработки / П.В. Медведев, В.А. Федотов, И.А. Бочкарева // Международный научно-исследовательский журнал. - 2015. - №7 (38). C. $77-80$.

12. Ахназарова С.Л. Методы оптимизации эксперимента в химической технике: Учебное пособие / С.Л. Ахназарова, В.В. Кафаров. - М.: Высшая школа, 1985. $-327 \mathrm{c}$.

Ободов Дмитрий Анатольевич - канд. техн. наук, доцент Института холода и биотехнологий ФГАОУ ВО «Санкт-Петербургский национальный исследовательский университет информационных технологий, механики и оптики», Россия, Санкт-Петербург.

Obodov Dmitry Anatolyevich - candidate of technical sciences, associate professor at the Institute of Refrigeration and Biotechnologies FSAEI of HE «Saint-Petersburg National Research University of Information Technologies, Mechanics and Optics», Russia, Saint-Petersburg.

Демидов Сергей Федорович - канд. техн. наук, доцент ФГАОУ ВО «Санкт-Петербургский национальный исследовательский университет информационных технологий, механики и оптики», Россия, Санкт-Петербург.

Demidov Sergey Fedorovich - candidate of technical sciences, associate professor FSAEI of HE «Saint-Petersburg National Research University of Information Technologies, Mechanics and Optics», Russia, Saint-Petersburg.

Савельев Владимир Андреевич - магистрант Института холода и биотехнологий ФГАОУ ВО «Санкт-Петербургский национальный исследовательский университет информационных технологий, механики и оптики», Россия, СанктПетербург.

Savelyev Vladimir Andreevich - graduate student at the Institute of Refrigeration and Biotechnologies FSAEI of HE «Saint-Petersburg National Research University of Information Technologies, Mechanics and Optics», Russia, Saint-Petersburg. 
Ивкина Александра Павловна - магистрант Института холода и биотехнологий ФГАОУ ВО «Санкт-Петербургский национальный исследовательский университет информационных технологий, механики и оптики», Россия, СанктПетербург.

Ivkina Alexandra Pavlovna - graduate student at the Institute of Refrigeration and Biotechnologies FSAEI of HE «Saint-Petersburg National Research University of Information Technologies, Mechanics and Optics», Russia, Saint-Petersburg. 